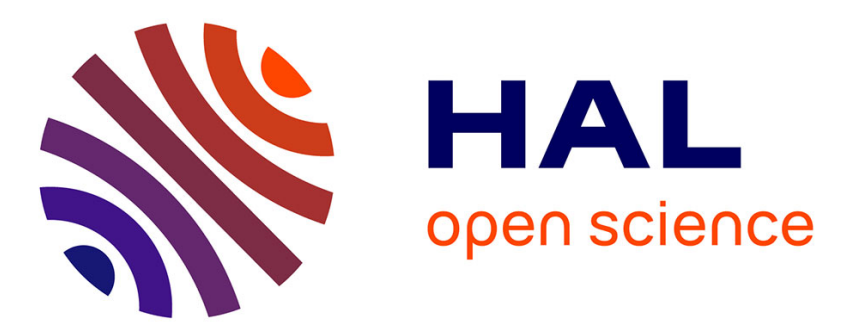

\title{
Exercise training reduces circulating adiponectin levels in patients with chronic heart failure
}

an M. van Berendoncks, Paul Beckers, Vicky Y. Hoymans, Nadine Possemiers, Floris L. Wuyts, Christiaan J. Vrints, Viviane M. Conraads

\section{- To cite this version:}

an M. van Berendoncks, Paul Beckers, Vicky Y. Hoymans, Nadine Possemiers, Floris L. Wuyts, et al.. Exercise training reduces circulating adiponectin levels in patients with chronic heart failure. Clinical Science, 2009, 118 (4), pp.281-289. 10.1042/CS20090213 . hal-00536332

\section{HAL Id: hal-00536332 \\ https://hal.science/hal-00536332}

Submitted on 16 Nov 2010

HAL is a multi-disciplinary open access archive for the deposit and dissemination of scientific research documents, whether they are published or not. The documents may come from teaching and research institutions in France or abroad, or from public or private research centers.
L'archive ouverte pluridisciplinaire HAL, est destinée au dépôt et à la diffusion de documents scientifiques de niveau recherche, publiés ou non, émanant des établissements d'enseignement et de recherche français ou étrangers, des laboratoires publics ou privés. 


\section{Exercise Training Reduces Circulating Adiponectin Levels \\ in Patients with Chronic Heart Failure.}

An M. Van Berendoncks, ${ }^{1,2,3}$ MD; Paul Beckers, ${ }^{1}$ PT, MSc; Vicky Y. Hoymans, ${ }^{1,2,3}$ PhD;

Nadine Possemiers, ${ }^{1}$ RN; Floris L. Wuyts, ${ }^{4} \mathrm{PhD}$; Christiaan J. Vrints, ${ }^{1,2,3} \mathrm{MD}, \mathrm{PhD}$;

Viviane M. Conraads, ${ }^{1,2,3} \mathrm{MD}, \mathrm{PhD}$

\footnotetext{
${ }^{1}$ Department of Cardiology, Antwerp University Hospital, Edegem, Belgium

${ }^{2}$ Laboratory for Cellular and Molecular Cardiology, Center for Cell Therapy and Regenerative Medicine (CCRG), Antwerp University Hospital, Edegem, Belgium

${ }^{3}$ University of Antwerp, Antwerp, Belgium

${ }^{4}$ Department of Biomedical Statistics, Antwerp University Hospital, Edegem, Belgium
}

Short title: Adiponectin and effect of exercise training in CHF

Key words: adiponectin - chronic heart failure - exercise training

\section{Correspondence to:}

An Van Berendoncks, MD

Department of Cardiology

Antwerp University Hospital

Wilrijkstraat 10, 2650 Edegem, Belgium

Tel: 003238214012 - Fax: 003238213974

E-mail: An.Vanberendoncks@ua.ac.be 


\section{Abstract}

Objective: High adiponectin concentrations have emerged as an independent risk factor for outcome in patients with chronic heart failure (CHF). Modification of adiponectin in CHF patients has not been assessed yet. We aimed to study the effect of exercise training on adiponectin levels in CHF patients.

Design: 80 patients with CHF due to systolic dysfunction were included; the effect of 4 months exercise training was studied in 46 patients, whereas the remaining 34 untrained CHF patients served as a sedentary control group. Circulating adiponectin concentrations, exercise capacity, anthropometric data and NT-proBNP levels were assessed.

Results: Adiponectin levels were significantly higher in CHF patients compared to healthy subjects (9.3 [7.1-16.1] $\mathrm{mg} / \mathrm{L}$ vs 4.9 [3.9-8.6] $\mathrm{mg} / \mathrm{L}, P=0.015)$. Stratification of CHF patients according to tertiles of NT-proBNP revealed an increase of adiponectin with disease severity $(P<0.0001)$. Exercise training reduced circulating adiponectin levels in CHF patients $(10.7$ [7.2-17.6] $\mathrm{mg} / \mathrm{L}$ before, 9.4 [5.9$14.8] \mathrm{mg} / \mathrm{L}$ after training $(P=0.013)$, whereas no changes were observed in the sedentary CHF group $(9.0[7.0-13.5] \mathrm{mg} / \mathrm{L}$ before, 10.1 [6.0-15.7] $\mathrm{mg} / \mathrm{L}$ after similar time interval (ns); $P=0.008$ for time and group interaction). Adiponectin concentrations were positively associated with NT-proBNP, HDL and correlated negatively with BMI, triglycerides and exercise capacity.

Conclusions: Circulating adiponectin concentrations are higher in CHF patients compared to healthy subjects and increase with disease severity. Four months exercise training lowers circulating adiponectin levels. 


\section{Introduction}

Chronic heart failure (CHF) is a complex syndrome of haemodynamic and neurohormonal abnormalities. Recently, the impact of insulin resistance on the progression of CHF[1] and the existence of a metabolic vicious cycle in heart failure[2] have been highlighted.

A hyperadrenergic state, characteristic of $\mathrm{CHF}$, initiates an adverse metabolic vicious cycle, whereby aberrant metabolism such as insulin resistance, further detrimentally affects disease progression.[2,3] Despite therapeutic advances, mortality and morbidity in CHF are still unacceptably high. Inefficient cardiac energy utilization and metabolic impairment in general, represent promising targets for $\mathrm{HF}$ therapy.[3] Physical training has emerged as one of the most efficient ways to improve physical capacity and quality of life in CHF patients. In addition, exercise training provides anti-remodelling effects, whereas meta-analyses strongly suggest survival benefit.[4] From a pathophysiological point of view, the fact that exercise training modulates inflammation, neuro-endocrine activation and oxidative stress in these patients is highly relevant.[5-8]

Adiponectin is an adipocyte-derived cytokine with insulin-sensitizing, anti-inflammatory and antiatherogenic properties.[9] Adiponectin levels are reduced in conditions such as diabetes mellitus type II, obesity, metabolic syndrome, hypertension and ischemic heart disease but increase following lifestyle adaptations such as weight loss or restricted energy intake. Opposed to these findings, in CHF, increased circulating levels of adiponectin have emerged as an independent risk factor for morbidity and mortality.[10-12] The mechanisms underlying this inverse relationship remain unexplained. Several speculations have been put forward, including adiponectin as a mere marker of disease severity $[10,13]$, the compensatory rise of adiponectin in response to inflammatory and metabolic disturbances in $\mathrm{CHF}[14,15]$, the association between adiponectin and natriuretic peptides[10,14,16] and the existence of an adiponectin resistance in CHF.[17]

Modification of adiponectin levels in CHF patients after intervention has not been studied yet. In the present study, we assessed circulating adiponectin concentrations in CHF patients, compared to controls, and evaluated the effects of a 4 months exercise training program. 


\section{Methods}

\section{Subjects and study design}

Eighty consecutive patients with CHF and systolic dysfunction due to ischemic or dilated cardiomyopathy were recruited from the Cardiac Rehabilitation Center and the outpatient Heart Failure Clinic of the University Hospital of Antwerp. Patients were included in this prospective, nonrandomized single center study if left ventricular ejection fraction (LVEF) was $<30 \%$ (assessed by echocardiography), if they were in NYHA functional class II-III and if they had been stable on medical treatment and symptoms for at least one month prior to inclusion. Exclusion criteria were: (1) recent acute coronary syndrome or revascularization $(<3$ months), valvular disease requiring surgery, exercise-induced myocardial ischemia or malignant ventricular arrhythmia, acute myocarditis or pericarditis, (2) cerebrovascular or musculoskeletal disease preventing exercise testing or training, (3) acute or chronic infections, allergies, cancer or inflammatory diseases and (4) diabetes mellitus. All data were assessed at baseline and after 4 months and consisted of clinical evaluation by a cardiologist (medical history, including medications used; New York Heart Association classification based on patient information; physical examination), echocardiography, collection of fasting blood samples and cardiopulmonary exercise testing (CPET). Previous CPET results and the patients' participation and grouping were blinded for the staff members. Medication remained unchanged during the study period.

The effect of exercise was studied in 46 CHF patients enrolled in a 4-months exercise training program at the Cardiac Rehabilitation Center. Thirty-four age- and gender matched CHF patients, attending the outpatient Heart Failure Clinic, served as an untrained heart failure control group. They had comparable disease severity, but were unable to attend the training program because of e.g. logistic problems. The same data were assessed in these patients before and after a similar time interval of 4 months. Ten age- and gender matched subjects served as a healthy baseline control group (no medication, no chronic underlying condition, no cardiac history, and no allergic condition). The study complies with the Declaration of Helsinki, the research protocol was approved by the local Ethics committee (Antwerp University Hospital) and written informed consent was obtained from all subjects.

\section{Exercise training}

Patients trained in hospital on an ambulatory base, three times/week, for 1 hour. The training session started with 5 minutes $(\mathrm{min})$ of warming-up and concluded with a 5 min cooling-down and stretching period. Two types of training programs were clinical practice at the time of inclusion: endurance training (ET) and combined endurance/resistance training (CT). Both training protocols have been described in detail previously.[18] They are routinely used and are considered standard treatment at our Rehabilitation Centre. Depending on patients' characteristics, such as severe muscle wasting, dynamic resistive exercises are incorporated in the training programme.

Briefly, for both CT and ET trained patients, endurance training target heart rate (THR) was calculated as $90 \%$ of the heart rate achieved at the anaerobic threshold. The initial resistance training intensity was set at $50 \%$ of 1 Repetitive Maximum (1RM) (for the 9 different muscle groups), with an increase to $60 \%$ after 2 months. Repetitions were slowly increased from $1 \times 10,1 \times 15,2 \times 10$ to $2 \times 15$. Between each series of repetitions 1 min rest was allowed. The ET group trained for 8 min on 5 different training devices (treadmill, bicycle, stair or step, arm-cycling, half recumbent or reclined cycling). When changing from one device to another, $2 \mathrm{~min}$ of recuperation time was introduced.

During the first 2 months, patients assigned to the CT group trained for almost 40 min on the Fitness equipment (Unica, Technogym, Gambetola, Italy), whereas only $10 \mathrm{~min}$ were spent on endurance training. The next 2 months, resistance training was reduced to 30 minutes ( 9 muscle groups, 2 times 15 repetitions each) and endurance training was increased to 2 times 8 min. 


\section{Measurements}

\section{Cardiopulmonary exercise testing (CPET)}

Symptom-limited CPET was performed on a treadmill (Medical Jaeger, Würzburg, Germany) in nonfasting condition and under medication. Depending on age, NYHA class and LVEF, 2 protocols were used, aiming at optimal exercise duration of 8-12 min. A ramp protocol starting with an equivalent of 20 or $40 \mathrm{~W}$ and incremental steps of 10 or $20 \mathrm{~W} / \mathrm{min}$, respectively, was used. Breath-by-breath gas exchange measurements permitted determination of ventilation (VE), oxygen uptake $\left(\mathrm{VO}_{2}\right)$ and carbon dioxide production $\left(\mathrm{VCO}_{2}\right)$ on-line (Cardiovit CS-200 Ergo-Spiro, Schiller AG, Baar, Switzerland). Patients were continuously monitored with twelve-lead ECG, whereas automatic blood pressure measurement was performed every 2 min. Peak oxygen consumption $\left(\mathrm{VO}_{2}\right.$ peak) was expressed as the highest attained $\mathrm{VO}_{2}$. CPETs were obtained at baseline and after 4 months. Body composition was assessed by bio-electrical impedance analysis (Omron body fat monitor BF300).[18]

\section{Biochemical analyses}

Fasting blood samples were collected between $0800 \mathrm{~h}$ and $0900 \mathrm{~h}$ at baseline and after 4 months. Creatinine, total cholesterol, triglycerides, LDL and HDL cholesterol levels were assessed immediately. Plasma was separated by centrifugation and aliquots were stored at $-20^{\circ} \mathrm{C}$.

Circulating adiponectin concentrations were measured using a commercially available enzyme-linked immunosorbent assay (ELISA) (Human adiponectin Quantikine Elisa, R\&D systems). Standards and samples were analyzed in duplicate according the manufacturer (sensitive assay with minimal detection limit of $0.246 \mu \mathrm{g} / \mathrm{L}$, intra-assay precision of $2.5 \%$ for mean $19.8 \mathrm{mg} / \mathrm{L}, \mathrm{SD} 0.50(\mathrm{n}=20)$ and inter-assay precision of 3.2 for mean $12.5, \mathrm{SD} 0.41(\mathrm{n}=40))$. Internal controls were included (Quantikine ${ }^{\circledR}$ ELISA kit Controls).

NT-proBNP was determined with a sandwich immunoassay on an Elecsys 2010 (Roche diagnostics, $\mathrm{GmbH}, 68298$ Mannheim, Germany). The analytical range extends from 5 to $35000 \mathrm{pg} / \mathrm{mL}$. The coefficient of variation was $1.3 \%(\mathrm{n}=10)$ at a level of $221 \mathrm{pg} / \mathrm{mL}$ and $1.2 \%(\mathrm{n}=10)$ at a level of 4091 $\mathrm{pg} / \mathrm{mL}$.

\section{Statistical analyses}

Results are expressed as mean value $\neq$ standard deviation or median (interquartile range) for nonGausian distributed parameters. The data were tested for normal distribution using the KolmogorovSmirnov test. Baseline characteristics of the groups were compared using the Student T test or MannWithney $U$ and Kruskal Wallis test for continuous variables, as appropriate. The $\chi^{2}$ test was used for categorical variables.

Pairwise comparisons (baseline versus 4 months) were carried out using the paired samples $\mathrm{T}$ test or Wilcoxon signed rank test. Differences between the 2 groups (trained versus untrained) and changes over time within each group (time effect), as well as any interaction (different trends over time between groups) were assessed by two-way repeated measures ANOVA. Linear regression analysis for the change in adiponectin was performed to identify possible relationships with other variables.

Because circulating levels of adiponectin, NT-proBNP, triglycerides, CRP and the measurements reflecting exercise capacity and LVEF were not normally distributed, correlations at baseline were determined with the non-parametric Spearman's correlation test. Multivariable linear regression analyses examining the correlates of circulating adiponectin levels, included baseline variables that were associated with adiponectin at the $P<0.05$ level in univariate analyses. $P$-value $<0.05$ was considered statistically significant. All statistical analyses were performed using the software package SPSS, version 16.0 (SPSS Inc.). 


\section{Results}

\section{Clinical characteristics (Table 1)}

Eighty CHF patients were recruited for this study. From the total group of 80 CHF patients, 46 consecutive patients were enrolled in a 4 months training program, whereas $34 \mathrm{CHF}$ patients served as an untrained CHF control group. As illustrated in Table 1, both CHF patient groups were well matched at baseline with respect to demographic characteristics, LVEF, functional NYHA class, etiology, comorbidities, medical treatment, $\mathrm{VO}_{2}$ peak and laboratory measurements. HDL values at baseline were significantly higher in the untrained CHF group.

\section{Circulating adiponectin levels}

For the total CHF population ( $\mathrm{n}=80$ ), adiponectin levels were significantly higher compared to healthy subjects $(\mathrm{n}=10$, mean age $60.8 \pm 5.0$ years, $60 \%$ males $)(9.3$ [7.1-16.1] $\mathrm{mg} / \mathrm{L}$ versus 4.9 [3.9-8.6] $\mathrm{mg} / \mathrm{L}, P=0.015)$. Stratification of CHF patients according to tertiles of NT-proBNP revealed a significant increase of adiponectin with disease severity $(P<0.0001)$ (Figure 1).

Adiponectin levels were significantly higher in female compared to male CHF patients (13.6 [9.519.3] $\mathrm{mg} / \mathrm{l}$ versus $8.2[5.1-13.9] \mathrm{mg} / \mathrm{l}, P<0.001)$. The presence of chronic renal failure did not influence circulating adiponectin levels in our CHF patients $(P>0.05)$. After stratification according to disease etiology (ischemic or idiopathic), no significant differences were found between both groups $(P>0.05)$.

\section{Effect of exercise}

Changes in exercise capacity and prognostic markers

Table 2 illustrates the significant beneficial effect of 4 months exercise training in terms of exercise capacity $\left(\mathrm{VO}_{2}\right.$ peak, Maximal Workload), work efficiency and NT-proBNP levels. Furthermore, NYHA functional class improved significantly $(P<0.05$ for interaction).

\section{Changes in anthropometric data and biochemical characteristics}

Training did not lead to a significant change in body weight or other anthropometric data (fat mass, lean body mass, waist and hip circumference). Lipoproteines remained unchanged, except for total cholesterol values which were significantly lower after 4 months of follow up in the untrained group (Table 2).

\section{Changes in adiponectin levels}

Exercise training significantly reduced circulating adiponectin levels in CHF patients (10.7 [7.2-17.6] $\mathrm{mg} / \mathrm{L}$ before, 9.4 [5.9-14.8] $\mathrm{mg} / \mathrm{L}$ after training) $(P=0.013)$, whereas no significant changes were observed in the untrained control CHF group $(9.0$ [7.0-13.5] mg/L before, $10.1[6.0-15.7] \mathrm{mg} / \mathrm{L}$ after similar time interval; $P=0.008$ for time $\mathrm{x}$ group interaction) (Figure 2).

Linear regression analysis for the change in adiponectin confirmed the independent effect of exercise training on the decrease in circulating adiponectin level, after adjustment for associated baseline variables (cfr next paragraph: NT-proBNP, HDL, BMI, parameters reflecting exercise capacity) and for the change in variables with a significant difference after exercise training (Table 2).

In this study, there was no difference in the type of exercise training (ET or CT) with respect to the adiponectin reduction ( $P=0.284$ for time and group interaction). 


\section{Correlations of adiponectin}

Adiponectin concentration measured at baseline in the total CHF group $(n=80)$ was positively associated with NT-proBNP (Figure 3), and inversely related to an atherogenic lipid profile (Trigycerides $\mathrm{r}=-0.493, P<0.0001$; HDL r=0.480, $P<0.0001$ ). As illustrated in Table 3 , a strong negative relation was found with anthropometric data, with the exception of fat mass.

Adiponectin correlated negatively with exercise capacity $\left(\mathrm{VO}_{2}\right.$ peak, maximal workload) (Table 3$)$. There were no significant correlations between adiponectin and LVEF, inflammatory parameters (CRP, sedimentation) or renal function.

On stepwise multivariable analyses, two parameters (i.e.; high NT-proBNP and HDL) were significant independent predictors of baseline circulating adiponectin levels (Table 3 ). 


\section{Discussion}

While previous studies have already demonstrated increased adiponectin concentrations in patients with CHF, our study is the first to evaluate the effect of exercise training on circulating adiponectin levels in CHF patients with systolic dysfunction. Several interesting findings emerged from the present study:

1. We demonstrated for the first time that adiponectin levels in CHF can be modified by exercise training. Modulation of adiponectin levels in CHF patients occurs independently of possible confounders such as baseline exercise capacity, LVEF, lipid profile and NT-proBNP levels.

2. Circulating adiponectin levels were related to several baseline clinical and laboratory parameters. There was a clear positive relation with NT-proBNP concentrations and HDL and a negative association with TG and BMI. The present study extends these findings by including exercise testing-derived prognostic markers and anthropometric parameters.

3. Our results confirm that CHF patients are characterized by elevated adiponectin levels, which increase with disease severity. These findings support a role for adiponectin as a biomarker in CHF.[11,14]

Adiponectin is an adipocytokine with known anti-inflammatory, anti-atherogenic and insulinsensitizing properties.[9] Adiponectin plasma levels have been found to be reduced in type 2 diabetics, in obese subjects and in patients with coronary artery disease. Moreover, lifestyle improvements, such as weight loss, increase adiponectin concentration. Paradoxically, in CHF patients, high adiponectin levels are associated with adverse outcome. Kistorp et al. showed for the first time in $195 \mathrm{CHF}$ patients that increased adiponectin is associated with poor outcome.[10] This finding has recently been confirmed by others, demonstrating that adiponectin is an independent prognostic predictor for mortality and morbidity in CHF.[11,15]

Despite all recently published observational data concerning adiponectin and CHF, the mechanisms for increased concentration of adiponectin in CHF remain to be elucidated.

\section{Causes of increased adiponectin levels in CHF}

Several hypotheses have been proposed to explain elevated adiponectin levels in CHF. CHF patients are characterized by numerous metabolic disturbances, among which insulin resistance and increased concentrations of free fatty acids (FFA) have been repeatedly demonstrated.[19,20] The existence of a hyperadrenergic state that increases the concentration of FFA in plasma in CHF patients has been identified years ago.[20] However, the crucial role of FFA in insulin resistance and its complications in the setting of $\mathrm{CHF}[2,16,21,22]$ have only recently gained attention. Since adiponectin regulates glucose and fatty acid metabolism, increased adiponectin secretion might be a compensatory mechanism to attenuate FFA-induced insulin resistance.[14,15]

CHF patients are marked by a chronic low-grade inflammatory state, characterized by increased levels of circulating pro-inflammatory cytokines. The well known anti-inflammatory effects of adiponectin point at a possible physiological response in an attempt to suppress inflammation. $[9,14]$

In accordance with previous studies[10,12-14], we also showed a strong positive relation between adiponectin levels and NT-proBNP concentrations. Adiponectin and natriuretic peptides behave similarly in CHF: both factors increase with disease severity, which makes these circulating peptides of great potential interest to serve as biomarkers and it might be hypothesized that their increase is a compensatory mechanism. Sengenes $\mathrm{C}$ et al.[23] identified a lipolytic and potential lipid-mobilizing effect of natriuretic peptides, mediated by specific adipocyte membrane receptors. It has been hypothesized that natriuretic peptides, through an increased lipid mobilization, indirectly stimulate adiponectin levels.[10] A recent study [16] demonstrated that exogenous ANP (carperitide) infusion for 7 days increased plasma total and HMW adiponectin, thereby supporting previous statements that natriuretic peptides increase adiponectin levels via a functional GC-A receptor. In addition, 2 recently 
published studies, dealing with the relationship between adiponectin and BNP, [24,25] endorse the fact that natriuretic peptides might have lipid mobilizing effects.

Another explanation implies the existence of a functional adiponectin resistance.[17] This hypothesis is supported by a recently published study showing a decreased mRNA and protein expression of the adiponectin receptor AdipoR1 in the left ventricle of infarcted mouse hearts compared to normal hearts.[26] Hyperadiponectinemia may reflect defective compensatory mechanisms to overcome this adiponectin resistance.

Contrary to the suggested compensatory mechanisms, Norrelund et al. suggested that high adiponectin might not be beneficial in patients with established CHF.[15] Based on the proposed role of adiponectin to increase energy expenditure and induce weight loss through a direct effect on the brain[27], recent studies consider high adiponectin levels as a marker of the wasting process that characterizes severely ill CHF patients.[10,15]

\section{Adiponectin and lipid profile}

Despite the paradoxical behavior of adiponectin in CHF in terms of prognostic relevance, the antiatherogenic association of adiponectin appears to be preserved. We found a positive and independent association between HDL and adiponectin, and a negative association with TG. Our results are consistent with the hypothesis of von Eynatten et al.[28], who postulated that adiponectin may mediate part of its proposed anti-atherogenic properties by influencing HDL concentrations.

Whereas an atherogenic lipid profile is a well known risk factors for the development of coronary artery disease and hence, of CHF, it has indeed been shown that once CHF is established, these factors may provide protection against further progression, a concept known as reverse epidemiology.[29] The remained anti-atherogenic property of adiponectin reflects the dyslipidemic state in CHF. Adiponectin might be increased to overcome this dyslipidemic state and thereby even worsening outcome in CHF patients. It might also be that adiponectin levels and the dyslipidemic profile are not etiologically linked to disease progression in $\mathrm{CHF}$, but that they are simply markers of disease severity.

\section{Adiponectin and effect of exercise training}

In the present study, there was a clear reduction of adiponectin levels in CHF patients following exercise training, independent of possible confounders such as gender, lean body mass, exercise capacity, lipid profile, LVEF and NT-proBNP. The clinical relevance of the decrease in adiponectin levels after exercise training is reflected in parallel and favourable changes in terms of exercise capacity as well as in a significant improvement of NYHA functional class. Additionally, we found an important association of adiponectin with anthropometric data, and exercise capacity, indicating the involvement of adiponectin in the regulation of whole-body energy metabolism.

This is the first study to investigate the modulation of adiponectin levels in CHF. Several hypotheses can be put forward to explain the observed effect. Firstly, the role of adiponectin in mitochondrial dysfunction might be relevant. The known impact of adiponectin on mitochondrial biogenesis in skeletal muscle[30], which is severely disrupted in CHF,[31] might be affected by exercise training. Physical exercise is known to improve aerobic metabolism in CHF[32] and to partly reverse mitochondrial abnormalities. A second hypothesis relies on the role of adiponectin in the metabolic impairment in CHF, characterized by insulin resistance and increased circulating levels of fatty acids.[15] Exercise training might break through this metabolic vicious cycle and conquer adiponectin resistance. Improvement of insulin resistance, which is a well-known effect of exercise training in healthy subjects and diabetics might subsequently result in lower adiponectin levels. In addition the anti-inflammatory role of exercise training, as demonstrated by our group[5] and others[6] could lower adiponectin levels. Finally, the demonstrated close relationship between circulating adiponectin and 
natriuretic peptides on the one hand, and the fact that exercise training lowers NT-proBNP levels,[7] supports the proposed co-regulatory role of FFA metabolism and natriuretic peptides.[14,33]

\section{Limitations}

Firstly, this study was designed as a prospective single-center study, comparing an exercise-trained CHF with an untrained CHF control group. Randomization between the 2 treatment options would have increased the strength of the conclusion. However, considering the clear benefit of exercise training in $\mathrm{CHF}$ and the fact that patients were specifically referred to a third-line Cardiac Rehabilitation Centre for exercise training, we considered randomization ethically unacceptable. Although the difference was not statistically significant, it may appear that our trained patients are more severely diseased. This notion is based on increased NT-proBNP levels and lower LVEF. However, another important prognostic parameter and indicator of disease severity, VO2 peak, was similar in both groups.

Secondly, 2 different training protocols were applied: Endurance training (ET) and Combined endurance - resistance training (CT). Both training modalities were routinely used and considered as standard treatment at our Rehabilitation Centre at the time of inclusion. Depending on patients' characteristics, such as severe muscle wasting, dynamic resistive exercises were incorporated in the training programme. This study aimed to investigate the effect of an intervention i.e. a training programme, on circulating adiponectin levels in the CHF population, without differentiation according to training modalities. A subanalysis performed in this study population did not detect any difference between type of exercise training (ET versus CT) on circulating adiponectin levels. However, we admit that this might be due to the relatively small numbers of patients in each training group. The elaboration of a possible differential effect of type of exercise training will be the subject of future studies.

Thirdly, the possible effect of drugs on circulating adiponectin levels should be taken into account. Angiotensin-converting enzyme-inhibitors have been reported to increase circulating adiponectin levels, whereas beta-blockers decrease adiponectin levels[34]. These drugs were however routinely prescribed to all CHF patients, with no significant differences in the use between the trained and untrained CHF patients. In addition, medical treatment was not changed during the study period. The effect of statins on circulating adiponectin levels is depending on the population studied and remains a controversial topic. The untrained CHF group in our study appears to have a higher percentage of statin intake. The treatment, however, was initiated well before enrolment in the study and remained stable during the study period. Therefore, it appears unlikely that this issue explains the evolution of adiponectin.

\section{Conclusions}

In conclusion, the present study for the first time demonstrated that high adiponectin levels are reduced following exercise training in patients with CHF. The importance of adiponectin in CHF might be extended from its role as a biomarker with proven prognostic value, to a pathophysiological link between the energetic (mitochondrial dysfunction) and metabolic (insulin resistance) abnormalities in CHF. Our findings, together with data from other studies, suggest that dysregulation of the adiponectin pathway contributes to the observed metabolic impairment in CHF. Further exploration of the adiponectin signalling pathway downstream the receptor in skeletal muscle might allow potential target-specific pharmacotherapy, and might provide fundamental insight in the modulatory role of exercise training. 


\section{Acknowledgements}

This research is supported by the Fund for Scientific Research, (FWO) - Flanders, (Belgium):

An Van Berendoncks is supported by a PhD fellowship grant, Paul Beckers is granted with a special $\mathrm{PhD}$ fellowship and Viviane Conraads is a Senior Clinical Investigator of the Research Foundation, (FWO) - Flanders, (Belgium).

We would like to thank Viviane Van Hoof, Manoe Martin and coworkers for assistance with the NTproBNP assays. We also express thanks to Kurt Wuyts for assistance in CPET, peripheral muscle strength measurements and the Cardiac Rehabilitation training programme.

\section{Conflicts of interest}

None declared. 


\section{References}

1. Doehner W, von Haehling S, Anker SD. Insulin Resistance in Chronic Heart Failure. (2008) J. Am. Coll. Cardiol. 52, 239-240

2. Opie LH. (2004) The metabolic vicious cycle in heart failure. Lancet 364, 1733-1734

3. Ashrafian H, Frenneaux MP, Opie LH. (2008) Metabolic Mechanisms in Heart Failure. Circulation 116, 434-448

4. Piepoli MF, Davos C, Francis DP, Coats AJ. (2004) Exercise training meta-analysis of trails in patients with chronic heart failure (ExTraMATCH). B.M.J. 328, 189

5. Conraads VM, Beckers P, Bosmans J, De Clerck LS, Stevens WJ, Vrints CJ, Brutsaert DL. (2002) Combined endurance/resistance training reduces plasma TNF-alpha receptor levels in patients with chronic heart failure and coronary artery disease. Eur. Heart J. 23, 1854-1860

6. Adamopoulos S, Parissis J, Karatzas D, Kroupis C, Georgiadis M, Karavolias G, Paraskevaidis J, Koniavitou K, Coats AJ, Kremastinos DT. (2002) Physical training modulates proinflammatory cytokines and the soluble Fas/soluble Fas ligand system in patients with chronic heart failure. J. Am. Coll. Cardiol. 39, 653-663

7. Conraads VM, Beckers P, Vaes J, Martin M, Van Hoof V, De Maeyer C, Possemiers N, Wuyts FL, Vrints CJ. (2004) Combined endurance/resistance training reduces NT-pro-BNP levels in patients with chronic heart failure. Eur. Heart J. 25, 1797-1805

8. Linke A, Adams V, Schulze PC, Erbs S, Gielen S, Fiehn E, Möbius-Winkler S, Schubert A, Schuler G, Hambrecht R. (2005) Antioxidative effects of exercise training in patients with chronic heart failure: increase in radical scavenger enzyme activity in skeletal muscle. Circulation 111, 1763-1770

9. Kadowaki T, Yamauchi T. (2005) Adiponectin and adiponectin receptors. Endocr. Rev. 26, 439-451

10. Kistorp C, Faber J, Galatius S, Gustafsson F, Frystyk J, Flyvbjerg A, Hildebrandt P. (2005) Plasma adiponectin, body mass index, and mortality in patients with chronic heart failure. Circulation 112, 1756-1762

11. George J, Patal S, Wexler D, Sharabi Y, Peleg E, Kamari Y, Grossman E, Sheps D, Keren G, Roth A. (2008) Circulating adiponectin concentrations in patients with congestive heart failure. Heart 92, 1420-1424

12. Tamura T, Furukawa Y, Taniguchi R, Sato Y, Ono K, Horiuchi H, Nakagawa Y, Kita T, Kimura T. (2008) Serum adiponectin level as an independent predictor of mortality in patients with congestive heart failure. Circ. J. 71, 623-630

13. Tsutamoto T, Tanaka T, Sakai H, Ishikawa, Fujii M, Yamamoto T, Horie M. (2007) Total and high molecular weight adiponectin, haemodynamics, and mortality in patients with chronic heart failure. Eur. Heart J. 28, 1723-1730

14. McEntegart MB, Awede B, Petrie MC, Sattar N, Dunn FG, MacFarlane NG, McMurray JJ. (2007) Increase in serum adiponectin concentrations in patients with heart failure and cachexia: relationship with leptin, other cytokines, and B-type natriuretic peptide. Eur. Heart J. 28, 829835

15. Nørrelund H, Wiggers H, Halbirk M, Frystyk J, Flyvbjerg A, Bøtker HE, Schmitz O, Jørgensen JO, Christiansen JS, Møller N. (2006) Abnormalities of whole body protein turnover, muscle metabolism and levels of metabolic hormones in patients with chronic heart failure. J. Intern. Med. 260, 11-26

16. Tanaka T, Tsutamoto T, Sakai H, Nishiyama K, Fujii M, Yamamoto T, Horie M. (2008) Effect of atrial natriuretic peptide on adiponectin in patients with heart failure. Eur. J. Heart Fail. 10, 360-366

17. Kintscher U. (2007) Does adiponectin resistance exist in chronic heart failure? Eur. Heart J. 28, 1676-1677

18. Beckers PJ, Denollet J, Possemiers NM, Wuyts FL, Vrints CJ, Conraads VM. (2008) Combined endurance-resistance training vs. endurance training in patients with chronic heart failure: a prospective randomized study. Eur. Heart J. 29, 1858-1866

19. Doehner W, Rauchhaus M, Ponikowski P, Godsland IF, von Haehling S, Okonko DO, Leyva F, Proudler AJ, Coats AJ, Anker SD. (2005) Impaired insulin sensitivity as an independent risk 
factor for mortality in patients with chronic heart failure. J. Am. Coll. Cardiol. 46, 1019-1026

20. Lommi J, Kupari M, Yki-järvinen H. (1998) Free-fatty acid kinetics and oxidation in congestive heart failure. Am. J. Cardiol. 81, 45-50

21. Shulman GI. (2000) Cellular mechanisms of insulin resistance. J. Clin. Invest. 106, 171-176

22. Murray AJ, Anderson RE, Watson GC, Radda GK, Clarke K. (2004) Uncoupling proteins in human heart. Lancet 364, 1786-1788

23. Sengenes C, Berlan M, De G I, Lafontan M, Galitzky J. (2000) Natriuretic peptides: a new lipolytic pathway in human adipocytes. FASEB J. 14, 1345-1351

24. Ang DS, Welsh P, Watt P, Nelson SM, Struthers A, Sattar N. (2009) Serial changes in adiponectin and BNP in ACS patients: paradoxical associations with each other and prognosis Clin. Science. 117, 41-48

25. Tsukamoto O, Fujita M, Kato M, Yamazaki S, Asano Y, Ogai A, Okazaki H, Asai M, Nagamachi Y, Maeda N, Shintani Y, Minamino T, Asakura M, Kishimoto I, Funahashi T, Tomoike H, Kitakaze M. (2009) Natriuretic peptides enhance the production of adiponectin in human adipocytes and in patients with chronic heart failure. J. Am. Coll. Cardiol. 53, 20702077

26. Von Haehling S, Doehner W, Anker SD. (2007) Nutrition, metabolism, and the complex pathophysiology of cachexia in chronic heart failure. Cardiovasc. Res. 73, 298-309

27. Qi Y, Takahashi N, Hileman SM, Patel HR, Berg AH, Pajvani UB, Scherer PE, Ahima RS. (2004) Adiponectin acts in the brain to decrease body weight. Nat. Med. 10, 524-529

28. von Eynatten M, Hamann A, Twardella D, Nawroth PP, Brenner H, Rothenbacher D. (2006) Relationship of adiponectin with markers of systemic inflammation, atherogenic dyslipidemia, and heart failure in patients with coronary heart disease. Clin. Chem. 52, 853-859

29. Kalantar-Zadeh K, Block G, Horwich T, Fonarow GC. (2004) Reverse epidemiology of conventional cardiovascular risk factors in patients with chronic heart failure. J. Am. Coll. Cardiol. 43, 1439-44

30. Civitarese AE, Ukropcova B, Carling S, Hulver M, DeFronzo RA, Mandarino L, Ravussin E, Smith SR. (2006) Role of adiponectin in human skeletal muscle bioenergetics. Cell. Metab. 4, 75-87

31. Mudd J O, Kass D A. (2008) Tackling heart failure in the twenty-first century. Nature 451, 919928

32. Ventura-Clapier R, Mettauer B, Bigard X. (2007) Beneficial effects of endurance training on cardiac and skeletal muscle energy metabolism in heart failure. Cardiovasc. Res. 73, 10-18

33. Haugen E, Furukwawa Y, Isic A, Fu M. (2008) Increased adiponectin level in parallel with increased NT-pro BNP in patients with severe heart failure in the elderly: A hospital cohort study. Int. J. Cardiol. 125, 216-219

34. Yamaji M, Tsutamoto T, Tanaka T, Kawahara C, Nishiyama K, Yamamoto T, Fujii M, Horie M. (2009) Effect of carvedilol on plasma adiponectin concentration in patients with chronic heart failure. Circ. J. 73, 1067-1073. 


\section{Figure legends}

Figure 1. Circulating adiponectin levels in CHF according to severity of disease versus healthy subjects

Baseline circulating adiponectin levels in $\mathrm{CHF}(\mathrm{n}=80)$ and healthy control subjects $(\mathrm{n}=10)$. CHF patients are divided in tertiles of baseline NT-proBNP levels, indicating increasing disease severity. Data provided are median with interquartile range and 5-95\% range. Differences among groups were analysed using Kruskal-Wallis testing.

Figure 2. Adiponectin levels before and after 4 months in the trained and the untrained control CHF group.

Comparisons of the delta change in adiponectin levels, VO2 peak and maximal workload before and after 4 months. Group I = Trained CHF patients $(\mathrm{n}=46)$. Group II = Untrained CHF control group (n $=34)$. Data provided are mean with SEM. $P$-values for time $\mathrm{x}$ group interaction.

\section{Figure 3. Baseline correlation NT-proBNP with adiponectin}

Scatterplot of the association between plasma adiponectin and plasma NT-proBNP levels. 
Table 1. Baseline Characteristics of CHF patients

\begin{tabular}{|c|c|c|c|c|}
\hline & CHF patients & Trained CHF & Untrained CHF & $P$-value \\
\hline & $(\mathrm{n}=80)$ & $(n=46)$ & $(\mathrm{n}=34)$ & \\
\hline \multicolumn{5}{|l|}{ Demographics } \\
\hline Age (years) & $59.0(11.2)$ & $57.5(10.8)$ & $61.1(11.6)$ & 0.158 \\
\hline Gender $(\%$ male $)$ & 65 & 70 & 59 & 0.319 \\
\hline $\operatorname{BMI}\left(\mathrm{kg} / \mathrm{m}^{2}\right)$ & $25.3(4.4)$ & $25.1(4.4)$ & $25.1(4.3)$ & 0.957 \\
\hline Serum creatinine (mg/dl) & $1.2(1.0-1.6)$ & $1.2(1.0-1.5)$ & $1.25(1.0-1.7)$ & 0.551 \\
\hline \multicolumn{5}{|l|}{ Heart failure measurements } \\
\hline LVEF (\%) & $18(15-23)$ & $17(14-22)$ & $19(15-24)$ & 0.115 \\
\hline NT-proBNP (pg/ml) & $1088(482-2757)$ & $1216(530-2887)$ & $833(373-2477)$ & 0.154 \\
\hline NYHA class $(\%$ class $2 / 3)$ & $77.5 / 22.5$ & $74 / 26$ & $82 / 18$ & 0.372 \\
\hline Etiology (\% ischemic) & 55 & 52 & 59 & 0.555 \\
\hline VO2 peak (ml/kg/min) & $19(16-24)$ & $19(15-24)$ & $20(16-24)$ & 0.381 \\
\hline \multicolumn{5}{|l|}{ Medication (\%) } \\
\hline Beta blocker & 75 & 70 & 82 & 0.192 \\
\hline ACE-I and / or ATII & 99 & 100 & 97 & 0.242 \\
\hline Diuretics & 84 & 80 & 88 & 0.350 \\
\hline Statins & 30 & & 41 & 0.061 \\
\hline \multicolumn{5}{|l|}{ Lipid status (mmol/L) } \\
\hline Total Cholesterol & $5.2(1.1)$ & $5.1(1.2)$ & $5.3(1.1)$ & 0.725 \\
\hline HDL & $1.3(0.4)$ & $1.2(0.3)$ & $1.4(0.4)$ & 0.045 \\
\hline LDL & $3.3(1.0)$ & $3.4(1.1)$ & $3.2(0.9)$ & 0.353 \\
\hline TG & $128(100-199)$ & $126(94-202)$ & $130(107-198)$ & 0.931 \\
\hline Adiponectin (mg/L) & $9.3(7.1-16.1)$ & $10.7(7.2-17.6)$ & $9.0(7.0-13.5)$ & 0.450 \\
\hline
\end{tabular}

BMI, Body mass index; LVEF, left yentricular ejection fraction; NT-proBNP, N-terminal pro-brain natriuretic peptide; NYHA, New York Heart Association classification, VO2 peak, peak oxygen consumption; ACE-I, Angiotensin-converting enzyme inhibitors; ATII, angiotensin II antagonists; TG, triglycerides. Differences between trained and untrained CHF group by Student's T-test, MannWhitney $\mathrm{U}$ or $\chi^{2}$ test, as appropriate. Data are expressed as mean (SD) or median (interquartile range). 
Table 2. Effect of exercise training

\begin{tabular}{|c|c|c|c|c|c|}
\hline & \multicolumn{2}{|c|}{$\begin{array}{l}\text { Trained group } \\
\quad(n=46)\end{array}$} & \multicolumn{2}{|c|}{$\begin{array}{l}\text { Untrained Group } \\
\quad(n=34)\end{array}$} & \multirow{2}{*}{ 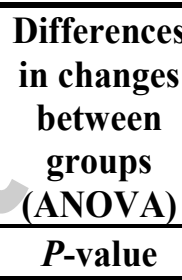 } \\
\hline & Baseline & 4 months & Baseline & 4 months & \\
\hline \multicolumn{6}{|l|}{ Prognostic markers } \\
\hline NT-proBNP (pg/ml) & $1216(530-2887)$ & $1186(385-2496)^{*}$ & $833(373-2477)$ & $976(420-2082)$ & 0.122 \\
\hline LVEF $(\%)$ & $17(14-22)$ & $17(14-23)$ & $19(15-24)$ & $19(15-27)$ & 0.276 \\
\hline NYHA class I /II / III (\%) & $0 / 74 / 26$ & $47 / 46 / 7 * * *$ & $0 / 82 / 18$ & $6 / 85 / 9$ & $<0.001$ \\
\hline \multicolumn{6}{|l|}{ Anthropometric data } \\
\hline $\operatorname{BMI}\left(\mathrm{kg} / \mathrm{m}^{2}\right)$ & $25.1(4.4)$ & $25.9(4.1)^{*}$ & $25.1(4.3)$ & $25.3(4.3)$ & 0.594 \\
\hline Waist circumference $(\mathrm{cm})$ & $90(15)$ & $90(14)$ & $86(16)$ & $88(18)$ & 0.553 \\
\hline Lean body mass $(\mathrm{kg})$ & $52(11)$ & $52(11)$ & $47(13)$ & $48(13)$ & 0.471 \\
\hline \multicolumn{6}{|l|}{ Maximal exercise capacity } \\
\hline $\mathrm{VO} 2$ peak $(\mathrm{ml} / \mathrm{kg} / \mathrm{min})$ & $19(15-24)$ & $21(16-25)^{* *}$ & $20(16-24)$ & $19(15-24)$ & 0.003 \\
\hline Maximal workload (watt) & $90(70-133)$ & $130(100-160)^{* * *}$ & $100(80-140)$ & $100(80-145)$ & $<0.001$ \\
\hline $\begin{array}{l}\text { Work efficiency } \\
(\text { watt / VO2 peak) } \\
\left(\text { Watt } \mathrm{ml}^{-1} \mathrm{~kg} \mathrm{~min}^{-1}\right)\end{array}$ & $5.0(4.5-5.7)$ & & $5.4(4.9-6.2)$ & $5.7(4.9-6.4)$ & $<0.001$ \\
\hline \multicolumn{6}{|l|}{$\begin{array}{l}\text { Biochemical data } \\
(\mathrm{mmol} / \mathrm{L})\end{array}$} \\
\hline Total cholesterol & $5.2(1.1)$ & $5.4(1.0)$ & $5.3(1.1)$ & $4.9(0.9)^{*}$ & 0.014 \\
\hline HDL & $1.2(0.3)$ & $1.3(0.4) * *$ & $1.4(0.4)$ & $1.4(0.3)$ & 0.088 \\
\hline LDL & $3.3(1.0)$ & $3.5(1.0)$ & $3.2(0.9)$ & $3.0(0.8)$ & 0.059 \\
\hline TG & $126(94-202)$ & $137(95-174)$ & $130(107-198)$ & $160(88-233)$ & 0.437 \\
\hline Adiponectin (mg/L) & $10.7(7.2-17.6)$ & $9.4(5.9-14.8)^{*}$ & $9.0(7.0-13.5)$ & $10.1(6.0-15.7)$ & 0.008 \\
\hline
\end{tabular}

*, $P<0.05 ; * *, P<0.01 ; * * *, P<0.001, P$-values of parameters at 4 months versus baseline within each group by Paired Samples T-test or Wilcoxon signed rank test. Data are expressed as mean (SD) or median (interquartile range)

Licenced copy. Copying is not permitted, except with prior permission and as allowed by law.

(C) 2009 The Authors Journal compilation @ 2009 Portland Press Limited 
Table 3. Baseline correlations with adiponectin

\begin{tabular}{lcccc}
\hline & $\begin{array}{c}\text { Univariate } \\
\text { correlation } \\
\text { coefficient }\end{array}$ & P-value & $\begin{array}{c}\text { Multi-variate } \\
\text { beta- } \\
\text { coefficient }\end{array}$ & P-value \\
\hline Gender $(\mathrm{male}=1$, female $=2)$ & 0.401 & $<0.0001$ & & \\
BMI $\left(\mathrm{kg} / \mathrm{m}^{2}\right)$ & -0.345 & 0.002 & & \\
Lean body mass $(\mathrm{kg})$ & -0.465 & 0.001 & & \\
Waist circumference $(\mathrm{cm})$ & -0.487 & $<0.0001$ & & $<0.0001$ \\
Waist - hip ratio & -0.414 & 0.003 & & \\
HDL $(\mathrm{mmol} / \mathrm{l})$ & 0.480 & $<0.0001$ & 0.663 & 0.001 \\
TG $(\mathrm{mmol} / \mathrm{l})$ & -0.493 & $<0.0001$ & & \\
NT-proBNP $(\mathrm{pg} / \mathrm{ml})$ & 0.481 & $<0.0001$ & 0.344 & \\
VO2 peak (ml/kg/min) & -0.392 & $<0.0001$ & & \\
Maximal wattage $(\mathrm{Watt})$ & -0.442 & $<0.0001$ & & \\
\hline
\end{tabular}

Licenced copy. Copying is not permitted, except with prior permission and as allowed by law. 


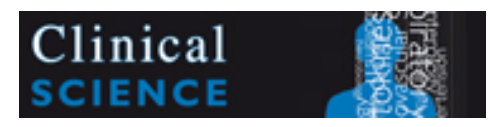

Figure 1

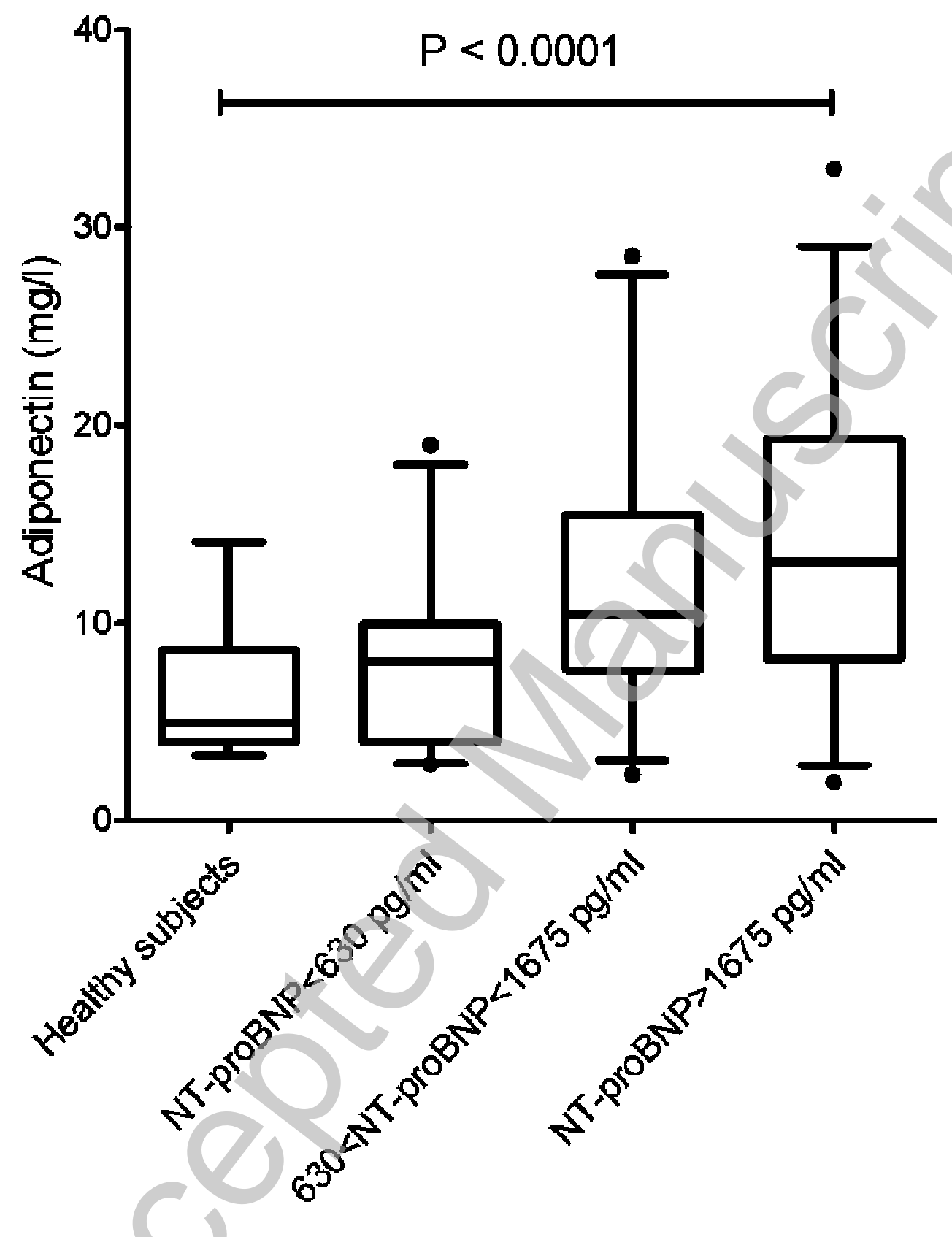




\section{Figure 2}

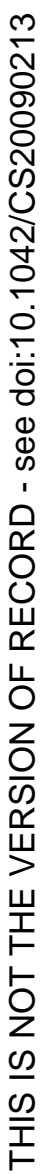

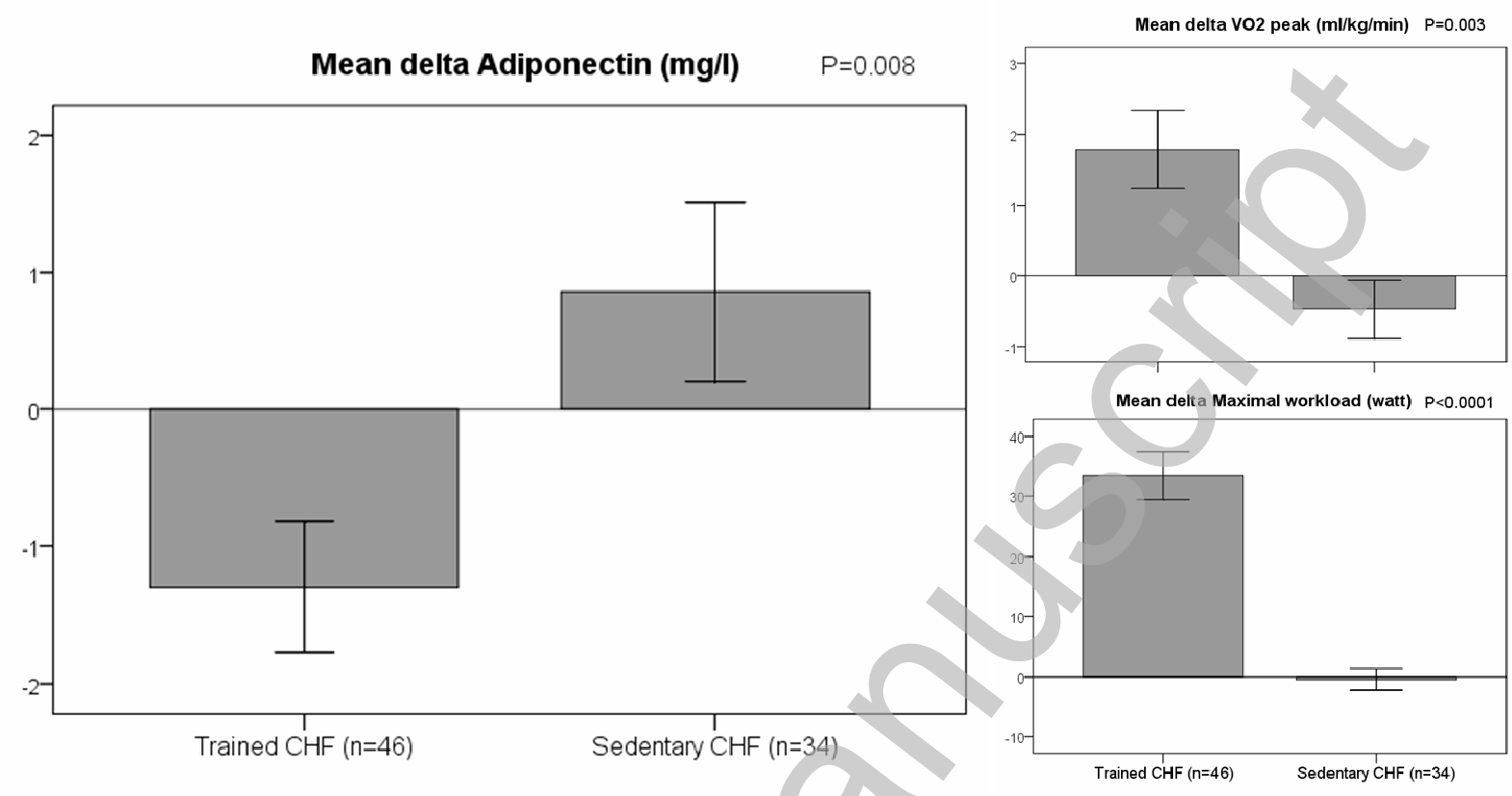

Licenced copy. Copying is not permitted, except with prior permission and as allowed by law. 
Figure 3

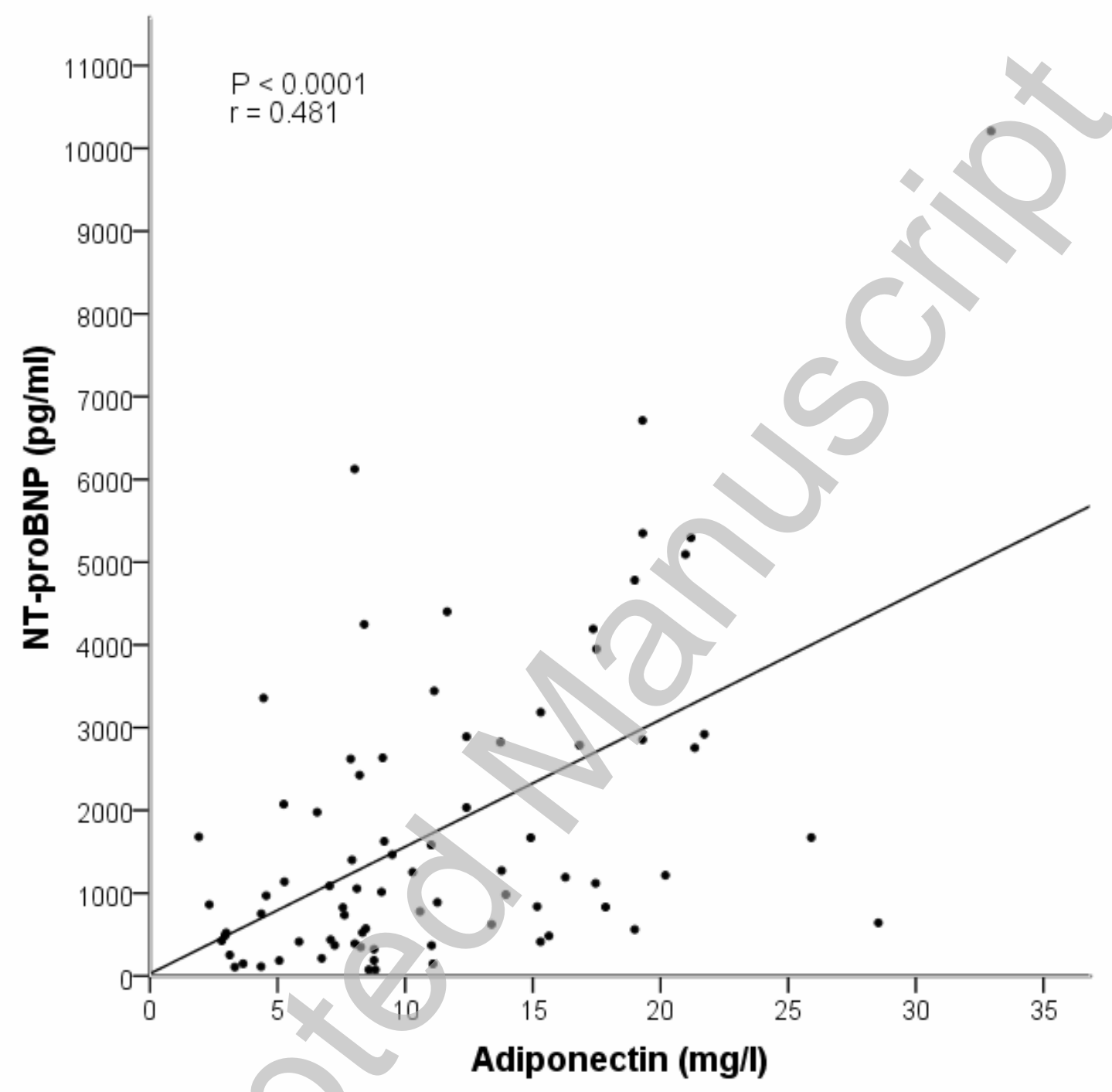

